09

\title{
Одновременное управление интенсивностью отраженного и прошедшего света в тонких пленках манганитов
}

\author{
( Ю.П. Сухоруков, ${ }^{1}$ А.В. Телегин, ${ }^{1}$ Е.А. Ганьшина ${ }^{2}$ \\ ${ }^{1}$ Институт фозики металлов им. М.Н. Михеева УрО РАН, \\ 620108 Екатеринбург, Россия \\ ${ }^{2}$ Московский государственный университет им. М.В. Ломоносова, \\ 119899 Москва, Россия \\ e-mail: telegin@imp.uran.ru
}

Поступило в Редакцию 3 декабря 2020 г.

В окончательной редакции 15 января 2021 г.

Принято к публикации 25 января 2021 г.

Описан способ одновременного управления магнитным полем интенсивностью отраженного и прошедшего неполяризованного света в пленках магнетиков, обладающих гигантскими эффектами магнитоотражения и магнитопропускания. Показаны преимущества предложенного способа перед способами раздельного управления интенсивностью пропускания или отражения света. Описаны спектральные, температурные и динамические диапазоны применения способа на примере пленок манганитов лантана.

Ключевые слова: магнитоотражение, магнитопропускание, манганиты, ИК-диапазон, неполяризованный свет, магнитооптические эффекты.

DOI: 10.21883/JTF.2021.06.50873.333-20

\section{Введение}

Хорошо известны различные способы управления интенсивностью оптического излучения, основанные на разных физических явлениях, когда характеристики оптической среды могут меняться под воздействием: электрического поля (эффекты Поккельса и Керра) [1-3], магнитного поля (эффект Фарадея и магнитооптический эффект Керра) [4-6], магнитоупругих и упругих напряжений (фотоупругость) [7-9] и т.д. Эффекты, связанные с отраженным светом (магнитоотражение, эффект Керра), как правило, малы по величине (до 1\% по абсолютной величине) и применяются в основном в специализированных задачах анализа электронных и магнитных характеристик непрозрачных сред. Преобладающее распространение получили эффекты, связанные с управлением интенсивностью линейно- или циркулярнополяризованного прошедшего света. В этом случае недостатком являются большие оптические потери в области фундаментального поглощения, в которой магнитооптические эффекты (МОЭ) в магнетиках достигают максимума. При увеличении длины волны в инфракрасной (ИК) области спектра МОЭ уменьшаются обратно пропорционально квадрату длины волны $\sim 1 /\left(\lambda-\lambda_{0}\right)^{2}$, где $\lambda_{0}$ - длина волны максимума фундаментального поглощения $[10,11]$. Увеличение толщины оптического элемента с целью увеличения МОЭ в прошедшем свете одновременно приводит и к увеличению оптических потерь. Дополнительные потери вносят также полосы примесного поглощения и остаточные лучи (интенсивные фононные и многофононные полосы поглощения [12]).
Компенсировать эти недостатки и повысить величину МОЭ позволяет способ, связанный с управлением интенсивностью неполяризованного света. Данный подход был реализован при использовании пленок легированных манганитов с колоссальным магнитосопротивлением [13], обладающих эффектами магнитопропускания или магнитопоглощения света [14]. Физический механизм возникновения магнитопропускания в манганитах связан с подавлением магнитным полем флуктуаций магнитных моментов носителей заряда вблизи магнитного фазового перехода. Это сопровождается уменьшением электросопротивления (переход изолятор-металл) и увеличением поглощения света в области взаимодействия со свободными носителями заряда. Обнаружение большого эффекта магнитоотражения неполяризованного света в манганитах [15] позволило расширить арсенал способов управления интенсивностью оптического излучения, используя эффекты магнитоотражения и магнитопропускания одновременно на одном магнитооптическом элементе.

Кроме того, в тонких пленках и многослойных структурах можно получить дополнительное усиление МОЭ за счет отражения света от границы раздела оптических сред пленка-подложка и особенностей пленочного состояния. Например, в монокристаллах $\mathrm{La}_{0.7} \mathrm{Ca}_{0.3} \mathrm{MnO}_{3}$ магнитопропускание не наблюдается из-за больших оптических потерь, а магнитоотражение составляет менее $4 \%$, тогда как в пленках $\mathrm{La}_{0.7} \mathrm{Ca}_{0.3} \mathrm{MnO}_{3}$ магнитоотражение и магнитопропускание достигает 10-20\% [16].

В настоящей работе на примере пленок легированных манганитов лантана приводится описание и показано преимущество способа одновременного управления ин- 
тенсивностью отраженного и прошедшего неполяризованного света в магнетиках перед способом раздельного управления интенсивностью света.

\section{1. Описание способа}

Способ одновременного управления интенсивностью отраженного и прошедшего света основан на использовании больших по величине эффектов магнитоотражения $(\Delta R / R)$ и магнитопропускания $(\Delta t / t)$ неполяризованного света в пленках манганитов с колоссальным магнитосопротивлением. Эти магнитооптические эффекты связаны с относительным изменением интенсивности отражения $(R)$ и пропускания $(t)$ оптического излучения при наличии и отсутствии магнитного поля $H$ (выражения (1) и (2)). В ИК-области спектра, области взаимодействия света с носителями заряда, эти эффекты в манганитах пропорциональны величине магнитосопротивления [17]:

$$
\begin{gathered}
\frac{\Delta t}{t}=\frac{t_{H}-t}{t} \approx \frac{1}{2} \frac{\Delta \rho}{2 \rho} t, \\
\frac{\Delta R}{R}=\frac{R_{H}-R}{R} \approx-(1-R) \frac{\Delta \rho}{\rho},
\end{gathered}
$$

где $t_{H}, R_{H}$ и $\rho_{H}-$ коэффициенты пропускания, отражения оптического излучения и удельное электросопротивление в магнитном поле. Выражения (1) и (2) демонстрируют, что $\Delta R / R$ и $\Delta t / t$ позволяют бесконтактно оптическими методами контролировать изменение электросопротивления в электрической цепи за счет изменения магнитного потока.

Принципиальная схема устройства для реализации способа одновременного управления интенсивностью отраженного и прошедшего света в магнитооптическом элементе из пленки манганита (рис. 1) мало отличается от аналогичной для устройства с раздельным управлением этими параметрами. Угол падения света $(\theta)$ на оптический элемент может составлять от $5^{\circ}$ до $75^{\circ}$. С одной стороны, его величина ограничена углом

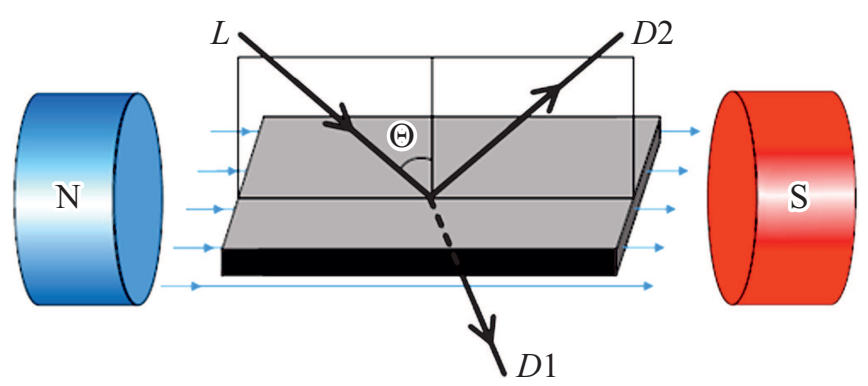

Рис. 1. Схематическое изображение способа одновременного управления внешним магнитным полем интенсивностью отраженного и прошедшего света в пленке манганита, обладающей эффектами магнитоотражения и магнитопропускания. $L-$ излучатель, $D 1$ и $D 2-$ приемники прошедшего и отраженного света, $\theta-$ угол падения излучения к нормали в плоскости падения. Тонкими стрелками показан магнитный поток.
Брюстера (максимум для отраженного и минимум для прошедшего света [12]), с другой стороны - минимальным углом регистрации, обусловленным измерительной схемой и габаритами источника и детектора излучения. Для получения минимальных оптических потерь предлагается использовать угол $\theta \sim 5^{\circ}-7^{\circ}$.

Основным магнитооптическим элементом при реализации способа одновременного управления интенсивностью отраженного и прошедшего света являются тонкие пленки легированного манганита лантана, обладающие эффектами магнитоотражения и магнитопропускания неполяризованного света. Максимальные величины эффектов достигаются в высококачественных пленках манганитов, обладающих наибольшим объемом ферромагнитной фазы, выраженным переходом металл-изолятор и наибольшей температурой Кюри $\left(T_{\mathrm{C}}\right)$. Величину $T_{\mathrm{C}}$ можно менять как не изовалентным замещением $\mathrm{La}^{3+}$, например, ионами $\mathrm{K}^{+}, \mathrm{Na}^{+}, \mathrm{Ag}^{+}, \mathrm{Ba}^{2+}, \mathrm{Ca}^{2+}, \mathrm{Sr}^{2+}$, так и изовалентным замещением $\mathrm{La}^{3+}$ ионами редкой земли, например, $\mathrm{Pr}^{3+}$. В последнем случае величины эффектов практически не меняются при замещении La до 50\% [14]. В таблице приведено несколько примеров легированных составов и $T_{\mathrm{C}}$ пленок манганитов на монокристаллических подложках (данные взяты из обзора [14]).

Предложенный способ может быть рекомендован к применению в широкой спектральной области длин волн, включающей в себя видимый и ИК-диапазоны. Формирование спектров $\Delta R / R$ и $\Delta t / t$ в видимой области спектра (область фундаментального поглощения) определяется изменением под действием поля электронной структуры манганита, а в ИК-области - взаимодействия света со свободными носителями заряда. В качестве примера на рис. 2 представлены спектры $\Delta R / R$ и $\Delta t / t$ для пленок № 1-3 из таблицы. Очевидное преимущество пленки состава $\mathrm{La}_{0.7} \mathrm{Ca}_{0.3} \mathrm{MnO}_{3}$ для практического использования, скорее всего, обусловлено меньшей дефектностью по сравнению с другими пленками. Исследования показали, что в высококачественных пленках $\mathrm{La}_{0.7} \mathrm{Ca}_{0.3} \mathrm{MnO}_{3}$ эффекты $\Delta R / R$ и $\Delta t / t$ кратно превышают значения МОЭ пленок других составов при прочих близких параметрах $[14,16]$. Уменьшение толщины пленки до $50 \mathrm{~nm}$, меньшей расчетной толщины псевдоморфного слоя $(\sim 80 \mathrm{~nm})$, демонстрирует возможность уменьшения оптических потерь при сохранении большой величины МОЭ. В работе [16] на основании сравнительного анализа спектральных, полевых и температурных зависимостей магнитоотражения в монокристаллах и пленках манганитов одинакового состава $\mathrm{La}_{0.7} \mathrm{Ca}_{0.3} \mathrm{MnO}_{3}$ было показано, что в пленках имеет место усиление $\Delta R / R$ и $\Delta t / t$ по сравнению с монокристаллами. Такое усиление было связано с дополнительным вкладом света, отраженного от границы раздела пленка-подложка. Отметим, что эффективность применения описываемого способа в различных частях спектра будет разной. Наблюдаемые в спектрах $\Delta R / R$ и $\Delta t / t$ для пленок манганитов резкие особенности со сменой знака эффектов обусловлены изменением под 
Толщина $d$, температура Кюри $T_{\mathrm{C}}$, магнитосопротивление $\Delta \rho / \rho$ (в поле, приложенном в плоскости образца $\left.H_{p}=6.4 \cdot 10^{5} \mathrm{~A} / \mathrm{m}\right)$, максимумы магнитоотражения $\Delta R / R\left(H_{p}=3.2 \cdot 10^{5} \mathrm{~A} / \mathrm{m}\right.$, длине волны $\left.\lambda \sim 15-17 \mu \mathrm{m}\right)$ и магнитопропускания $\Delta t / t$ (в поле, приложенном перпендикулярно плоскости образца $H_{s}=6.4 \cdot 10^{5} \mathrm{~A} / \mathrm{m}$ и $\lambda \sim 6 \mu \mathrm{m}$ ) пленок манганитов

\begin{tabular}{c|l|c|c|c|c|c}
\hline № пленки & \multicolumn{1}{|c|}{ Состав пленки/подложки } & $d, \mathrm{~nm}$ & $T_{C}, \mathrm{~K}$ & $\Delta \rho / \rho, \%$ & $\Delta t / t, \%$ & $\Delta R / R, \%$ \\
\hline 1 & $\mathrm{La}_{2 / 3} \mathrm{Ba}_{1 / 3} \mathrm{MnO}_{3} / \mathrm{SrTiO}_{3}$ & 110 & 320 & -15 & -8 & +5 \\
2 & $\mathrm{La}_{0.82} \mathrm{~K}_{0.18} \mathrm{MnO}_{3} / \mathrm{SrTiO}_{3}$ & 100 & $\sim 270$ & -19 & -5.5 & +6 \\
3 & $\mathrm{La}_{0.7} \mathrm{Ca}_{0.3} \mathrm{MnO}_{3} / \mathrm{LaAlO}_{3}$ & 320 & 265 & -30 & -30 & +22 \\
4 & $\left(\mathrm{La}_{0.75} \mathrm{Pr}_{0.25}\right)_{0.7} \mathrm{Ca}_{0.3} \mathrm{MnO}_{3} / \mathrm{SrTiO}_{3}$ & 300 & 214 & -45 & -25 & - \\
5 & $\left(\mathrm{La}_{0.5} \mathrm{Pr}_{0.5}\right)_{0.7} \mathrm{Ca}_{0.3} \mathrm{MnO}_{3} / \mathrm{LaAlO}_{3}$ & 300 & 179 & -60 & -23 & -
\end{tabular}

действием поля интенсивности и положения полос фундаментального, примесного и фононного поглощения. Отметим, что величины $\Delta R / R$ и $\Delta t / t$ для манганитов в ИК-области спектра существенно превышают изменение интенсивностей линейных магнитооптических эффектов в видимой области $[6,8,9,18]$. Таким образом, предлагаемый способ преимущественно можно использовать в оптоэлектронных устройствах ближнего и среднего ИКдиапазона.

Рис. 2 также демонстрирует существенное увеличение надежности регистрации оптического сигнала по сравнению со способом раздельного управления интенсивностью света. Например, пленка $\mathrm{La}_{0.7} \mathrm{Ca}_{0.3} \mathrm{MnO}_{3}$ обладает большими эффектами магнитопропускания и магнитоотражения (порядка 2\%) в видимом диапазоне. Однако при этом имеются и большие оптические потери на поглощение света. В ИК-диапазоне прозрачность пленки увеличивается и достигает порядка $30 \%$, а магнитоотражение и магнитопропускание - 15-20\%. Вместе с тем в диапазоне длин волн $0.8 \leq \lambda \leq 1.6 \mu \mathrm{m}$ магнитоот-

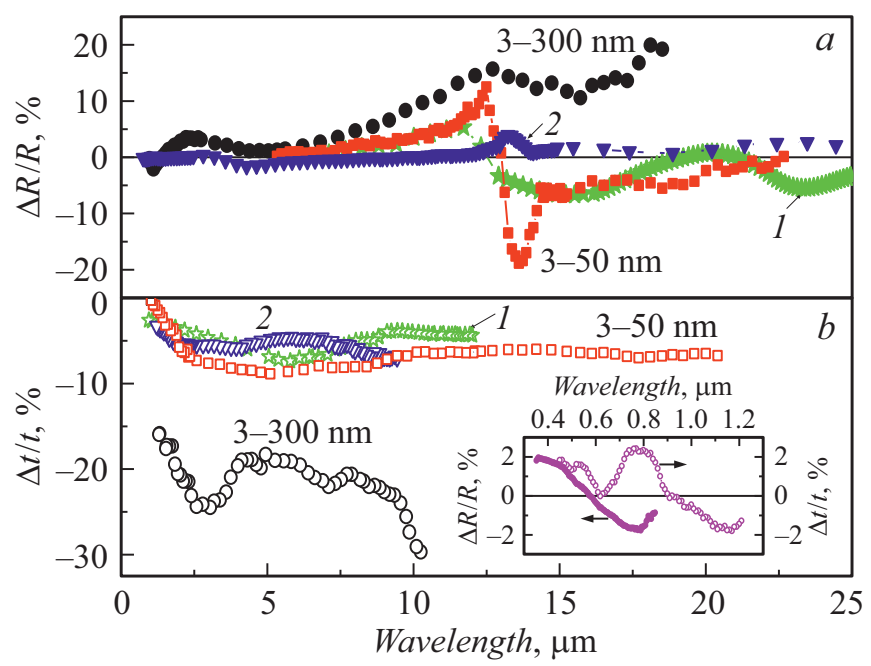

Pис. 2. Спектры: $a-$ магнитоотражения $\Delta R / R$ при $H_{s}=2.4 \cdot 10^{5} \mathrm{~A} / \mathrm{m}$ и $b-$ магнитопропускания $\Delta t / t$ при $H_{p}=6.4 \cdot 10^{5} \mathrm{~A} / \mathrm{m}$ для пленок $1-\mathrm{La}_{2 / 3} \mathrm{Ba}_{1 / 3} \mathrm{MnO}_{3}, 2-$ $\mathrm{La}_{0.82} \mathrm{~K}_{0.18} \mathrm{MnO}_{3}$ и $3-\mathrm{La}_{0.7} \mathrm{Ca}_{0.3} \mathrm{MnO}_{3}$ разной толщины при $T \approx T_{\mathrm{C}}$ (на вставке - спектры магнитопропускания и магнитоотражения пленки 3 в видимом диапазоне при $T \approx T_{\mathrm{C}}$ и $\left.H_{s}=2.8 \cdot 10^{5} \mathrm{~A} / \mathrm{m}\right)$.

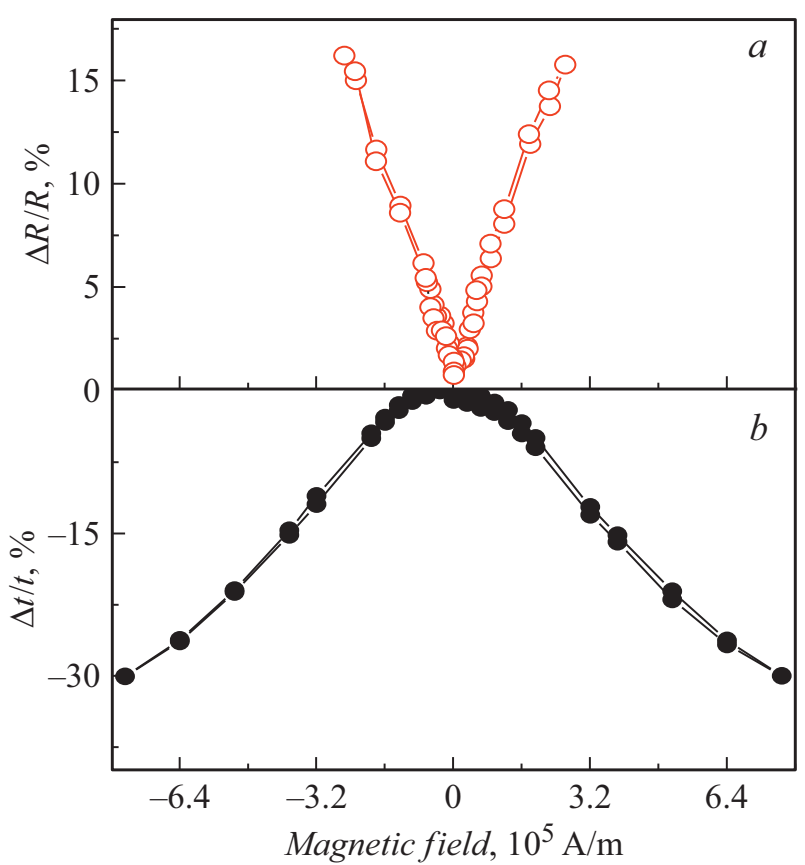

Рис. 3. Полевые зависимости: $a-$ магнитоотражения $\Delta R / R$ при длине волны $\lambda=12.5 \mu \mathrm{m}$ и $b-$ магнитопропускания $\Delta t / t$ при $\lambda=3 \mu$ m и $T \sim T_{\mathrm{C}}$ - для пленки $\mathrm{La}_{0.7} \mathrm{Ca}_{0.3} \mathrm{MnO}_{3}$ толщиной $d=300 \mathrm{~nm}$.

ражение менее $1 \%$ и является ненадежным параметром из-за малой величины, тогда как магнитопропускание составляет порядка $15 \%$ и является более надежным параметром при одновременной их регистрации.

Таким образом, одновременное изменение $\Delta R / R$ и $\Delta t / t$ как расширяет спектральный диапазон реализации предлагаемого способа, так и повышает помехоустойчивость оптической системы.

Следующим элементом предлагаемого способа является источник магнитного поля, в магнитный поток которого помещается пленка манганита. Таким источником может быть не только электромагнит (рис. 1), но и высокотоковые цепи, в том числе импульсные и подобные им устройства. Важной особенностью способа является наличие близкой к линейной зависимости от поля эффектов $\Delta R / R$ при $H_{s}>8 \cdot 10^{3} \mathrm{~A} / \mathrm{m}$ и $\Delta t / t$ при $H_{p}>8 \cdot 10^{4} \mathrm{~A} / \mathrm{m}$ (рис. 3 ) в широкой спектральной 


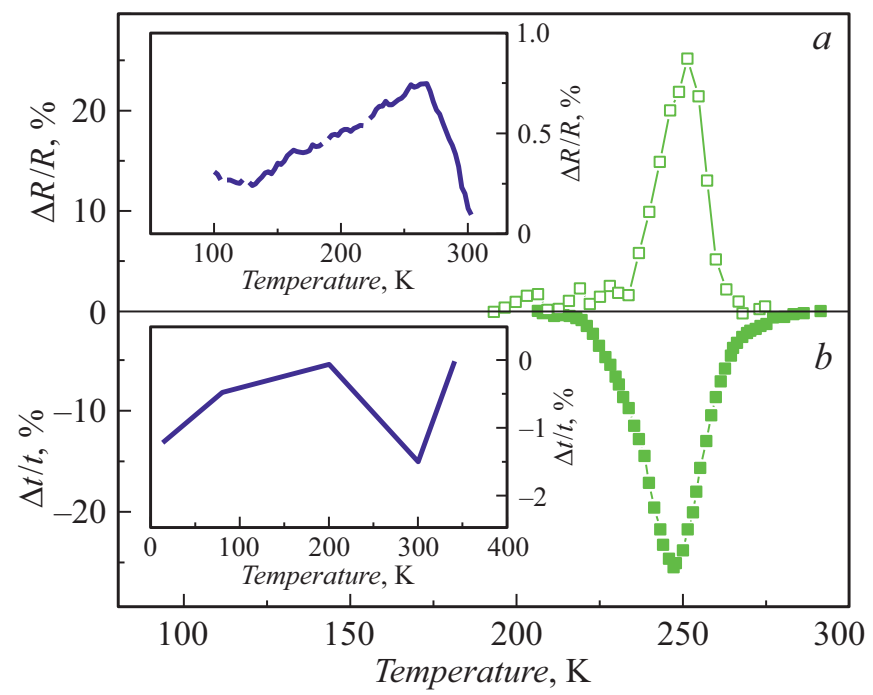

Рис. 4. Температурные зависимости: $a-$ магнитоотражения $\Delta R / R_{0}$ при $\lambda=12.5 \mu \mathrm{m}, H_{p}=2.8 \cdot 10^{5} \mathrm{~A} / \mathrm{m}$ и $b-$ магнитопропускания $\Delta t / t$ при $\lambda=3 \mu \mathrm{m}$ и $H_{s}=6.4 \cdot 10^{5} \mathrm{~A} / \mathrm{m}$ для пленки $\mathrm{La}_{0.7} \mathrm{Ca}_{0.3} \mathrm{MnO}_{3}$. На вставках $\Delta R / R$ и $\Delta t / t$ соответственно для пленки с вариантной структурой $\left(\mathrm{La}_{2 / 3} \mathrm{Ba}_{1 / 3} \mathrm{MnO}_{3} / \mathrm{ZrO}_{2}\left(\mathrm{Y}_{2} \mathrm{O}_{3}\right)\right.$ в поле $H_{p}=2.8 \cdot 10^{5} \mathrm{~A} / \mathrm{m}$.

области от 1 до $21 \mu \mathrm{m}$, что упрощает условия реализации способа в различных оптоэлектронных устройствах. Другой важной особенностью является четность полевых зависимостей эффектов (рис. 3). В случае переменных магнитных полей величины $\Delta R / R$ и $\Delta t / t$ будут меняться с частотой, равной удвоенной частоте поля.

Быстродействие предлагаемого в настоящей работе способа определяется процессами перемагничивания пленок манганитов и техническими возможностями коммутации магнитного поля [19]. Проведенные нами исследования показали, что в переменных магнитных полях до $\omega=1 \mathrm{kHz}$ магнитопропускание имеет те же значения, что и в постоянном магнитном поле. Сделаем оценку быстродействия предлагаемого способа. Данные по прохождению электромагнитных волн в манганитах $\mathrm{La}_{0.67} \mathrm{~Pb}_{0.33} \mathrm{MnO}_{3}$ и $\mathrm{La}_{0.60} \mathrm{Y}_{0.07} \mathrm{Ba}_{0.33} \mathrm{MnO}_{3}$ показали, что увеличение частоты электромагнитного поля до $10 \mathrm{MHz}$ не приводит к уменьшению величины магнитосопротивления [19]. Скорость перемагничивания пленки манганита в переменном магнитном поле в первом приближении определяется величиной скинслоя $\delta=(2 \rho / \omega \mu)^{1 / 2}$, где $\rho-$ удельное электросопротивление, $\omega$ - частота переменного магнитного поля и $\mu-$ магнитная проницаемость. Таким образом, при условии $\delta>d=300 \mathrm{~nm}$ предельная скорость перемагничивания пленки $\mathrm{La}_{0.7} \mathrm{Ca}_{0.3} \mathrm{MnO}_{3}$ при $T=265 \mathrm{~K}$ может достичь $\omega \sim 10^{9} \mathrm{~Hz}$ при $\mu \leq 5$ и $\rho=10^{-4} \Omega \mathrm{m}[15]$.

Мы полагаем, что быстродействие предлагаемого способа можно повысить до $10^{15} \mathrm{~Hz}$ при условии использования импульсных лазеров в качестве источника излуче- ния [20]. Такое предположение позволил сделать анализ фотоиндуцированного перехода металл-изолятор (МИ) и динамики проводимости пленок манганитов методом „накачка-зондирование“ [21]. Динамический интервал фотоиндуцированных эффектов от единиц пикосекунд до десятков фемтосекунд в таких пленках определяется вкладом термически разупорядоченных фононов при низких температурах и спиновых флуктуаций электронов вблизи $T_{\mathrm{C}}$ [22]. Выше температуры магнитного упорядочения в манганитах проявляется влияние фотоиндуцированной оптической анизотропии за счет вклада орбитального упорядочения. Помимо фотоиндуцированных эффектов существует также прямое воздействие импульсов лазера на решеточные моды в окрестности магнитного фазового перехода [23]. Для разработки способа сверхбыстрого управления интенсивностью света необходимым является дальнейшее исследование динамики эффектов магнитопропускания и магнитоотражения в тонкопленочных структурах на основе манганитов.

Температурная область применения предлагаемого способа определяется физическими механизмами, ответственными за возникновение магнитосопротивления и связанных с ним эффектов $\Delta R / R$ и $\Delta t / t$ в манганитах. Основной механизм связан с подавлением магнитным полем флуктуаций магнитных моментов носителей заряда, максимальных в узком температурном интервале вблизи $T_{\mathrm{C}}[13,14]$. Величина $\Delta \rho / \rho$ в манганитах достигает в максимуме десятков процентов и отлична от нуля в диапазоне температур $\pm 10-30^{\circ} \mathrm{C}$. В соответствие с выражениями (1) и (2) такое же температурное поведение имеют $\Delta R / R$ и $\Delta t / t$ (рис. 4). Другой механизм связан с влиянием магнитного поля на процессы туннелирования (рассеяния) спин-поляризованных носителей заряда через границы структурных доменов в пленках с вариантной структурой [24]. Туннельное магнитосопротивление и связанные с ним $\Delta R / R$ и $\Delta t / t$ достигают максимума вблизи нуля Кельвина. На вставках рис. 4 приведены температурные зависимости $\Delta R / R$ и $\Delta t / t$ для пленки $\mathrm{La}_{2 / 3} \mathrm{Ba}_{1 / 3} \mathrm{MnO}_{3}$ с вариантной структурой. Видно, что помимо максимума вблизи $T_{\mathrm{C}}$ существует слабый низкотемпературный рост эффектов $\Delta R / R$ и $\Delta t / t$ при $T<120 \mathrm{~K}$ (рис. 4), связанный с туннельным магнитосопротивлением [25].

Таким образом, существует возможность значительного увеличения температурной области применения предлагаемого способа за счет привлечения дополнительных механизмов рассеяния. Однако включение второго механизма приводит к уменьшению значений $\Delta R / R$ и $\Delta t / t$ вблизи $T_{\mathrm{C}}$ и росту поглощения света вследствие рассеяния света на границах структурных доменов и высокой дефектности пленок. Для решения этой проблемы необходимо провести исследование влияния послеростовых отжигов и магнитной анизотропии пленок с вариантой структурой. 


\section{Заключение}

Предложен способ одновременного управления магнитным полем интенсивностью отраженного (магнитоотражение) и прошедшего (магнитопропускание) неполяризованного света в пленках манганитов, обладающих колоссальным магнитосопротивлением. Физические механизмы, ответственные за появление магнитоотражения и магнитопропускания, определяют рабочие характеристики предлагаемого способа и связаны: с (i) подавлением магнитным полем флуктуаций магнитных моментов носителей заряда вблизи магнитного фазового перехода, (ii) с изменением под действием поля процессов туннелирования (рассеяния) спин-поляризованных носителей заряда. Показано, что способ может быть применен в широком видимом и ИК-спектральном диапазоне длин волн от 0.3 до $21 \mu \mathrm{m}$, температурном интервале от температур жидкого гелия до $360 \mathrm{~K}$ в магнитных полях $H \sim(3-6) \cdot 10^{5} \mathrm{~A} / \mathrm{m}$.

Реализация способа одновременного управления интенсивностью отраженного и прошедшего света возможна только при применении тонкопленочных структур. Предложенный способ имеет ряд преимуществ перед способом раздельного управления отраженным и прошедшим светом и позволяет: (i) увеличить надежность обработки оптического сигнала, (ii) усилить устойчивость оптической системы к оптическим помехам, (iii) расширить спектральный и температурный диапазоны и оставить неизменными размеры рабочего оптоэлектронного устройства. Быстродействие предложенного способа ограничено техническими характеристиками источника магнитного потока, детектора и излучателя.

\section{Финансирование работы}

Работа выполнена в рамках государственного задания МИНОБРНАУКИ России (тема „Спин“ № АААА-А18118020290104-2).

\section{Конфликт интересов}

Авторы заявляют, что у них нет конфликта интересов.

\section{Список литературы}

[1] Е.Р. Мустель, В.Н. Парыгин. Методы модулящии и сканирования света (Наука, М., 1970)

[2] В.В. Рандошкин, А.Я. Червоненкис. Прикладная магнитооптика (Энергоатомиздат, М., 1990)

[3] А.Н. Георгобиани. Соросовский образовательный журнал, 7 (6) 75 (2001).

[4] Ф.Ф. Сизов, Ю.И. Уханов. Магнитооптические эффекты Фарадея и Фохта в применении к полупроводникам (Наукова Думка, Киев, 1979)
[5] А.В. Телегин, Ю.П. Сухоруков, В.Д. Бессонов, С.В. Наумов. Письма в ЖТФ, 45 (12) 19 (2019). DOI: 10.21883/JTF.2021.06.50873.333-20

[A.V. Telegin, Yu.P. Sukhorukov, V.D. Bessonov, S.V. Naumov. Tech. Phys. Lett., 45 (6), 601 (2019). DOI: $10.1134 / \mathrm{S} 1063785019060300]$

[6] Е.А. Ганьшина, А.В. Зенков, Г.С. Кринчик, А.С. Москвин, А.Ю. Трифонов. ЖЭТФ, 99, 274 (1991). [Е.А. Gan'shina, A.V. Zenkov, G.S. Krinchik, A.S. Moskvin, A.Yu. Trifonov. JETP, 72 (1), 154 (1991)]

[7] T. Haider. Int. J. Electromagnet. Appl., 7 (1) 17 (2017). DOI:10.5923/j.ijea.20170701.03

[8] А.К. Звездин, В.А. Котов. Магнитооптика тонких пленок (Наука, М., 1988)

[9] Г.А. Смоленский, Р.В. Писарев, И.Г. Синий. УФН, 116, 231 (1975). DOI:11.3367/UFNr.0116.197506b.0231 [G.A. Smolenskii, R.V. Pisarev, I.G. Sinii. Sov. Phys. Usp., 18, 410 (1975). DOI: 10.1070/PU1975v018n06ABEH001964]

[10] J. Suits. IEEE Tr. Magn., 8 (1), 95 (1972). DOI: 10.1109/TMAG.1972.1067270

[11] S.D. Smith. Encyclopedia of physics: Light and matter Ia // Encyclopedia of Physics XXV/2a ed S. Flugge and L. Genzel (Springer-Verlag, Berlin-Heidelberg, NY., 1967)

[12] Ю.И. Уханов. Оптические свойства полупроводников (Наука, М., 1977)

[13] Н.Г. Бебенин, Р.И. Зайнуллина, В.В. Устинов. УФН, 188, 801 (2018). DOI:10.3367/UFNr.2017.07.038180

[N.G. Bebenin, R.I. Zainullina, V.V. Ustinov. Phys. Usp., 61, 719 (2018). DOI: 10.3367/UFNe.2017.07.038180]

[14] A.B. Granovsky, Yu.P. Sukhorukov, E.A. Gan'shina, A.V. Telegin. In Magnetophotonics: From Theory to Applications Magnetophotonic (Berlin, Heidelberg, Germany, Springer Series in Materials Science, 2013), 178.

[15] Ю.П. Сухоруков, Н.Н. Лошкарева, А.В. Телегин, Е.В. Мостовщикова, В.Л. Кузнецов, А.Р. Кауль, О.Ю. Горбенко, Е.А. Ганьшина, А.Н. Виноградов. Письма в ЖТФ, 29 (21), 55 (2003). [Yu.P. Sukhorukov, N.N. Loshkareva, A.V. Telegin, E.V. Mostovshchikova, V.L. Kuznetsov, A.R. Kaul', O.Yu. Gorbenko, E.A. Gan'shina, A.N. Vinogradov. Tech. Phys. Lett., 29 (11), 904 (2003)]

[16] А.Б. Грановский, Ю.П. Сухоруков, А.В. Телегин, В.Д. Бессонов, Е.А. Ганьшина, А.Р. Кауль, И.Е. Корсаков, О.Ю. Горбенко, J. Gonzalez. ЖЭТФ, 139 (1), 90 (2011).

[A.B. Granovskii, Yu.P. Sukhorukov, A.V. Telegin, V.D. Bessonov, E.A. Gan'shina, A.R. Kaul', I.E. Korsakov, O.Yu. Gorbenko, J. Gonzalez. JETP, 112 (1), 77 (2011)]

DOI: $10.1134 / \mathrm{S} 106377611005105 \mathrm{X}$

[17] А.Н. Юрасов, А.В. Телегин, Ю.П. Сухоруков. ФТТ, 58 (4), 656 (2016). [A.N. Yurasov, A.V. Telegin, Yu.P. Sukhorukov. Physics Solid State, 58 (4), 674 (2016).] DOI: $10.1134 / \mathrm{S} 1063783416040326$

[18] S. Sugano, N. Kojima (ed). Magneto-Optics, Springer Series in Solid-State Sciences (Springer, Berlin, 2000).

[19] A. Rinkevich, A. Nossov, V. Ustinov, V. Vassiliev, S. Petukhov. J. Appl. Phys., 91 (6), 3693 (2002). DOI: 10.1063/1.1448883

[20] A.V. Kimel, A.M. Kalashnikova, A. Pogrebna, A.K. Zvezdin. Physics Reports, 852, 1 (2020). DOI: $10.1016 /$ j.physrep.2020.01.004

[21] P. Munkhbaatar, Z. Marton, B. Tsermaa, W.S. Choi, Sung S. Ambrose Seo, J.S. Kim, N. Nakagawa, H.Y. Hwang, H.N. Lee, K. Myung-Whun. Appl. Phys. Lett., 106, 092907 (2015). DOI: $10.1063 / 1.4914094$ 
[22] R.D. Averitt, A.I. Lobad, C. Kwon, S.A. Trugman, V.K. Thorsmølle, A.J. Taylor. Phys. Rev. Lett., 87, 017401 (2001). DOI: 10.1103/PhysRevLett.87.017401

[23] M. Först, R.I. Tobey, S. Wall, H. Bromberger, V. Khanna, A.L. Cavalieri, Y.-D. Chuang, W.S. Lee, R. Moore, W.F. Schlotter, J.J. Turner, O. Krupin, M. Trigo, H. Zheng, J.F. Mitchell, S.S. Dhesi, J.P. Hill, A. Cavalleri. Phys. Rev. B, 84, 241104(R) (2011). DOI:10.1103/PhysRevB.84.241104

[24] А.Р. Кауль, О.Ю. Горбенко, А.А. Каменев. Усп. хим., 73 (9) 932 (2004). [A.R. Kaul, O.Y. Gorbenko, A.A. Kamenev. Russ. Chem. Rev., 73 (9), 861 (2004)]

[25] А.В. Телегин, В.А. Бессонова, Ю.П. Сухоруков, А.П. Носов, Е.А. Ганьшина. Опт. и спектр., 128 (1), 43 (2020). DOI: 10.21883/JTF.2021.06.50873.333-20

[A.V. Telegin, V.A. Bessonova, Y.P. Sukhorukov, A.P. Nosov, E.A. Gan'shina. Opt. and Spectr., 128 (1), 42 (2020).

DOI: 10.1134/S0030400X20010233] 